Braz J Med Biol Res, September 2012, Volume 45(9) 827-833

doi: 10.1590/S0100-879X2012007500093

Furosemide is associated with acute kidney injury in critically ill patients

T.M. Levi, M.S. Rocha, D.N. Almeida, R.T.C. Martins, M.G.C. Silva, N.C.P. Santana, I.T. Sanjuan and C.M.S. Cruz

The Brazilian Journal of Medical and Biological Research is partially financed by

\section{Q}

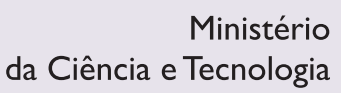

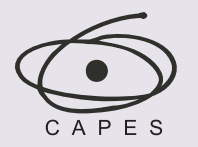

Ministério da Educação
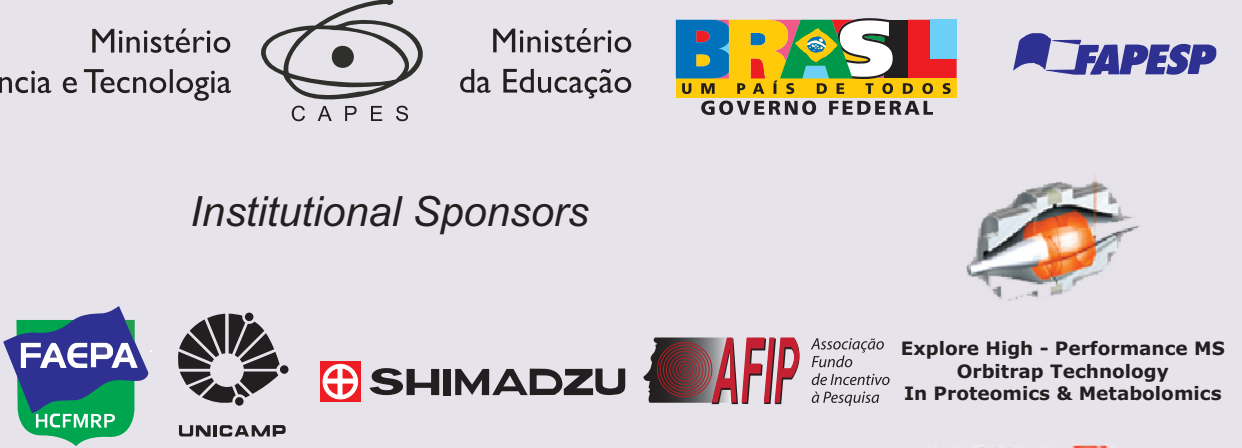

Institutional Sponsors

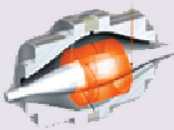

$\oplus$ SHIMADZU UNICAMP

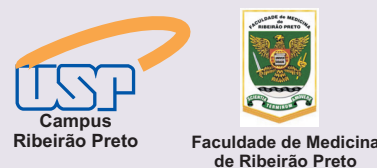
de Ribeirão Preto 


\title{
Furosemide is associated with acute kidney injury in critically ill patients
}

\author{
T.M. Levi ${ }^{1,2}$, M.S. Rocha ${ }^{3}$, D.N. Almeida4 ${ }^{4}$, R.T.C. Martins ${ }^{5}$, M.G.C. Silva 6 , \\ N.C.P. Santana ${ }^{6}$, I.T. Sanjuan ${ }^{6}$ and C.M.S. Cruz ${ }^{3,7}$ \\ ${ }^{1}$ Departamento de Ciências da Saúde, Universidade Estadual de Santa Cruz, Ilhéus, BA, Brasil \\ ${ }^{2}$ Departamento de Ciências da Saúde, União Metropolitana de Educação e Cultura, Itabuna, BA, Brasil \\ 3Pós-Graduação em Medicina e Saúde Humana, Escola Bahiana de Medicina e Saúde Pública, Salvador, BA, Brasil \\ ${ }^{4}$ Centro de Tratamento Intensivo, Hospital Calixto Midlej Filho, Itabuna, BA, Brasil \\ ${ }^{5}$ Departamento de Clínica Médica, Universidade Federal da Bahia, Salvador, BA, Brasil \\ ${ }^{6}$ Departamento de Clínica Médica, Escola Bahiana de Medicina e Saúde Pública, Salvador, BA, Brasil \\ ${ }^{7}$ Pesquisa Multidisciplinar, Hospital Santo Antonio, Obras Sociais Irmã Dulce, Salvador, BA, Brasil
}

\begin{abstract}
Acute kidney injury (AKI) is common in critically ill patients. Diuretics are used without any evidence demonstrating a beneficial effect on renal function. The objective of the present study is to determine the incidence of AKI in an intensive care unit (ICU) and if there is an association between the use of furosemide and the development of AKI. The study involved a hospital cohort in which 344 patients were consecutively enrolled from January 2010 to January 2011. A total of 132 patients (75 females and 57 males, average age 64 years) remained for analysis. Most exclusions were related to ICU discharge in the first $24 \mathrm{~h}$. Laboratory, sociodemographic and clinical data were collected until the development of AKI, medical discharge or patient death. The incidence of $\mathrm{AKI}$ was $55 \%(95 \% \mathrm{Cl}=46-64)$. The predictors of $\mathrm{AKI}$ found by univariate analysis were septic shock: OR $=3.12$, $95 \% \mathrm{Cl}=1.36-7.14$; use of furosemide: $\mathrm{OR}=3.27,95 \% \mathrm{Cl}=1.57-6.80$, and age: $\mathrm{OR}=1.02,95 \% \mathrm{Cl}=1.00-1.04$. Analysis of the subgroup of patients with septic shock showed that the odds ratio of furosemide was $5.5(95 \% \mathrm{Cl}=1.16-26.02)$ for development of AKI. Age, use of furosemide, and septic shock were predictors of AKI in critically ill patients. Use of furosemide in the subgroup of patients with sepsis/septic shock increased (68.4\%) the chance of development of AKI when compared to the sample as a whole $(43.9 \%)$
\end{abstract}

Key words: Acute renal failure; Critically ill patients; Furosemide; Septic shock

\section{Introduction}

Acute kidney injury (AKI) is characterized by an abrupt decline in glomerular filtration rate (GFR), manifested clinically as a sustained rise in serum creatinine and reduction in urine output. It may also be accompanied by a retention of nitrogen products and electrolyte disturbances (1-3).

The incidence of AKI varies between 36 and $67 \%$ among critically ill patients. Despite technological advances in clinical care, the prognosis for patients with AKI in intensive care units (ICU) is poor (4). About 5 to $6 \%$ of these cases require renal replacement therapy with a mortality rate of approximately 50 to $70 \%(5)$.

The etiology of AKI in the ICU is often multifactorial and therefore it is difficult to determine a single cause. In this context, there are interactions between clinical conditions that are fundamental for the development of AKI such as sepsis, hypovolemia, and other nephrotoxic drugs. AKI due to sepsis represents about $50 \%$ of cases in the ICU and is often accompanied by multiple organic dysfunction syndrome (1-5).

Loop diuretics are often used in patients with AKI in the ICU in an attempt to convert oliguric acute renal injury to non-oliguric injury. Despite the widespread use of this practice, there is little evidence that furosemide provides benefits for patients with acute renal injury (6-8). We hypothesize that the use of furosemide is associated with the development of $\mathrm{AKI}$ in critically ill patients. To test this hypothesis, we have determined the incidence of AKI in an ICU in the Brazilian Northeast focusing on the association between the use of furosemide and the development of AKI.

\section{Material and Methods}

The study was conducted on a hospital cohort in an

Correspondence: C.M.S. Cruz, Rua Plínio Moscoso, 486/502, 40155-810 Salvador, BA, Brasil. E-mail: constancacruz@yahoo.com.br

Received August 12, 2011. Accepted May 21, 2012. Available online June 1, 2012. Published August 17, 2012. 
ICU, Northeast Brazil. A total of 344 patients older than 18 years admitted consecutively were included in the study from January 2010 to January 2011. Two hundred and twelve patients were excluded: 55 were discharged during the first $24 \mathrm{~h} ; 76$ had baseline creatinine $>1.2 \mathrm{mg} / \mathrm{dL}$ on admission; 32 had only one serum creatinine determination during hospitalization; 24 did not agree to participate; 19 were dependent on chronic dialysis; 3 had AKI on admission; 2 had a diagnosis of brain death within the first $24 \mathrm{~h}$ after admission, and 1 was excluded because of missing data. Thus, a total of 132 patients remained for final analysis.

AKI was defined according to Mehta et al. (2) and Uchino et al. (9) who studied the effects of furosemide in patients with AKI in the ICU. The following criteria were used: 1) absolute increase in serum creatinine $\geq 0.3 \mathrm{mg} /$ $\mathrm{dL}$ or $\geq 1.5$ times the baseline level, or 2) requirement for renal replacement therapy, or 3 ) oliguria defined as urine output $<400 \mathrm{~mL}$ in $24 \mathrm{~h}$.

Data were collected on admission and daily during hospitalization until discharge or death. The dependent variable was the development of AKI. Independent variables were: age, gender, ethnicity, patient origin, serum creatinine and potassium, urine output, APACHE II score, multiple trauma, heart failure, sepsis/septic shock or not, presence of infection, daily fluid volume, urine output/day, medications and dosages, mean arterial pressure (MAP), furosemide doses, time of furosemide use in days, days of hospitalization, use of mechanical ventilation, potentially nephrotoxic medications such as nonsteroidal anti-inflammatory hormones, antibiotics, antifungals, immunosuppressants, antivirals, chemotherapeutic agents, diuretics other than furosemide, converting enzyme inhibitors, angiotensin receptor blockers, vasoactive drugs, and iodinated contrast agents.

\section{Statistical analysis}

SPSS version 17.0 (Statistical Package for Social Sciences) was used for data analysis. Descriptive statistics were used to determine frequencies, central tendency measures and dispersion measures related to the clinical, demographic and laboratory characteristics of patients.

We used the Shapiro-Wilk test to assess the type of distribution of variables. The chi-square test was used to compare proportions and the Student $t$-test to compare means. The Mann-Whitney test was used for comparison of maximum median creatinine, time of use, and dose of furosemide. We used the Spearman coefficient to check the correlation between total dose of furosemide and maximum creatinine.

Logistic regression analysis was used to identify predictors of $\mathrm{AKI}$ and to control confounding variables. The clinic-demographic characteristics that differed between the furosemide and non-furosemide groups ( $P$ value $<0.10$ ) were included in the model. Age and sepsis/septic shock were also included in the model because they were previously described as predictors of AKI in critically ill patients.
Univariate analysis was performed and factors with a $P$ value $<0.10$ remained for the multivariate model. Interactions were determined using a multivariate logistic regression model. We adopted $\alpha$ of 0.05 for all statistical analyses.

The study was approved by the Ethics Committee of Hospital Calixto Midlej Filho, Santa Casa de Misericórdia, Itabuna, BA, Brazil, and all patients gave written informed consent.

\section{Results}

The estimated incidence of $\mathrm{AKI}$ was $55 \%(95 \% \mathrm{Cl}=$ 46-64). Clinical-demographic characteristics of the patients such as age, ethnicity, MAP, heart rate (HR), $\mathrm{PaO}_{2} / \mathrm{FiO}_{2}$, hematocrit, and Glasgow score differed according to the use or not of furosemide (Table 1).

The average age of the group that used furosemide was 67.09 years vs 60.93 years for the group that did not use furosemide $(P=0.03)$. The female gender was more frequent in the group that used furosemide (55\%) and in the group that did not use furosemide (58\%). The most common ethnicity was Afrodescendent in the group that used furosemide $(67.24 \%)$ and in the group that did not use furosemide $(85.13 \%)(P=0.015)$.

MAP was $88.22 \mathrm{mmHg}$ in the group that used furosemide vs $96.22 \mathrm{mmHg}$ in the group that did not use it $(P=0.03)$. Mean HR was 96.38 in the group that used furosemide $v s$ 84.35 in the group that did not use it $(P=0.003)$.

The mean $\mathrm{PaO}_{2} / \mathrm{FiO}_{2}$ ratio was 268.80 for the group that used furosemide vs 322.75 for the group that did not use it $(P=0.02)$. The average hematocrit was $32.58 \%$ in the group that used furosemide vs $36.26 \%$ in the group that did not use it $(P=0.008)$. The mean Glasgow score was 11.54 for the group that used furosemide vs 12.58 in the group that did not use it $(P=0.09)$.

The predictors of $\mathrm{AKI}$ found in univariate analysis were septic shock: $\mathrm{OR}=3.12,95 \% \mathrm{Cl}=1.36-7.14$; use of furosemide: $\mathrm{OR}=3.27,95 \% \mathrm{Cl}=1.57-6.80$, and age: $\mathrm{OR}$ $=1.02,95 \% \mathrm{Cl}=1.00-1.04$ (Table 2 ).

Interaction was found between sepsis/septic shock and furosemide for the development of AKI in multivariate logistic regression analysis $(P=0.03)$. The total sample was subdivided into two subgroups as follows: presence of sepsis/ septic shock and absence of sepsis/septic shock.

When the subgroup sepsis/septic shock was analyzed, use of furosemide remained as a predictor of the development of AKI: $O R=5.5,95 \% \mathrm{Cl}=1.16-26.02$. However, when the subgroup without sepsis/septic shock was analyzed, the association between use of furosemide and development of AKI lost statistical significance: $\mathrm{OR}=2.1,95 \% \mathrm{Cl}$ $=0.88-5.02$.

The median time in days of use of furosemide for the development of AKI in the subgroup of patients without sepsis/septic shock was 3.0, interquartile range $(I Q R)=$ 6.0 vs $1.0, I Q R=3.0$ for patients who did not have $A K I(P=$ 
Table 1. Baseline characteristics of the cohort according to the use of furosemide $(N=132)$.

\begin{tabular}{|c|c|c|}
\hline Variable & Use of furosemide $(N=58)$ & Non-use of furosemide $(\mathrm{N}=74)$ \\
\hline Age (years) & $67.09 \pm 2.22^{*}$ & $60.93 \pm 1.88$ \\
\hline \multicolumn{3}{|l|}{ Gender } \\
\hline Female & $32 / 58(55 \%)$ & $43 / 74(58 \%)$ \\
\hline Male & $26 / 58(45 \%)$ & $31 / 74(42 \%)$ \\
\hline \multicolumn{3}{|l|}{ Ethnicity } \\
\hline Afrodescedent & $39 / 58(67.2 \%)^{*}$ & 63/74 (85.1\%) \\
\hline Caucasian & $19 / 58(32.8 \%)$ & $11 / 74(14.9 \%)$ \\
\hline \multicolumn{3}{|l|}{ Patient's origin } \\
\hline Surgical center & $21 / 58(36 \%)$ & $24 / 74(32 \%)$ \\
\hline Ward & $18 / 58(31 \%)$ & $22 / 74(30 \%)$ \\
\hline Emergency room & $12 / 58(21 \%)$ & $15 / 74(20 \%)$ \\
\hline Other hospital & $5 / 58(9 \%)$ & $5 / 74(7 \%)$ \\
\hline Cardiac catheterization & $2 / 58(3 \%)$ & $8 / 74(11 \%)$ \\
\hline Serum creatinine (mg/dL) & $0.88 \pm 0.23$ & $0.88 \pm 0.23$ \\
\hline Serum potassium (mEq/L) & $3.94 \pm 0.68$ & $3.95 \pm 0.80$ \\
\hline Fluid volume (mL/24 h) & $3530.12 \pm 1815.03$ & $3134.49 \pm 1512.84$ \\
\hline Urine output (mL/24 h) & $1593.98 \pm 975.64$ & $1742.69 \pm 1353.44$ \\
\hline Sepsis/septic shock & $15 / 58(26 \%)$ & 14/73 (19\%) \\
\hline Cardiogenic shock & $1 / 58(2 \%)$ & $0 / 74(0 \%)$ \\
\hline Cardiac failure & $31 / 58(53 \%)$ & $30 / 74(40 \%)$ \\
\hline Temperature $\left({ }^{\circ} \mathrm{C}\right)$ & $35.92 \pm 0.67$ & $36.09 \pm 0.84$ \\
\hline Mean arterial pressure $(\mathrm{mmHg})$ & $88.22 \pm 19.96^{*}$ & $96.22 \pm 21.38$ \\
\hline Heart rate & $96.38 \pm 25.77^{*}$ & $84.35 \pm 20.21$ \\
\hline Respiratory rate & $20.26 \pm 5.78$ & $19.17 \pm 7.30$ \\
\hline $\mathrm{PaO}_{2} / \mathrm{FiO}_{2}$ & $268.80 \pm 108.59^{*}$ & $322.75 \pm 137.13$ \\
\hline $\mathrm{pH}$ & $7.38 \pm 0.10$ & $7.4 \pm 0.09$ \\
\hline Serum sodium (mEq/L) & $142.17 \pm 4.45$ & $137.5 \pm 23.43$ \\
\hline Hematocrit (\%) & $32.58 \pm 5.14^{*}$ & $36.26 \pm 9.30$ \\
\hline Leukocyte levels $\left(\mathrm{mm}^{3}\right)$ & $12747.62 \pm 7210.48$ & $13708.09 \pm 15716.85$ \\
\hline Glasgow score & $11.54 \pm 3.32$ & $12.58 \pm 3.04$ \\
\hline
\end{tabular}

Continuous variables are reported as means \pm SD. Categoric variables are reported as valid percentages and absolute numbers. ${ }^{*} \mathrm{P}<0.05$ for the furosemide group compared to the non-furosemide group (chi-square test for proportions and Student $t$-test for means).

Table 2. Predictors of the development of acute kidney injury $(N=132)$.

\begin{tabular}{lcccc}
\hline Factor & Odds ratio & $95 \% \mathrm{Cl}$ & Adjusted odds ratio & $95 \% \mathrm{Cl}$ \\
\hline Age & 1.02 & $1.00-1.04$ & 1.01 & $0.98-1.04$ \\
Ethnicity & 0.9 & $0.39-2.04$ & - & - \\
$\mathrm{MAP} 1$ & 1.0 & $0.98-1.01$ & - & - \\
$\mathrm{PaO}_{2} / \mathrm{FiO}_{2}$ & 1.0 & $0.99-1.00$ & - & - \\
$\mathrm{Heart} \mathrm{rate}_{\text {Hematocrit }}$ & 1.0 & $0.98-1.01$ & - & - \\
Glasgow score & 0.94 & $0.88-0.99$ & - & - \\
MAP 2 & 0.84 & $0.74-0.96$ & 0.88 & $0.75-1.03$ \\
Sepsis/septic shock & 0.98 & $0.96-1.00$ & 0.99 & $0.97-1.03$ \\
Use of furosemide & 3.12 & $1.36-7.14$ & 0.76 & $0.14-4.05$ \\
Use of furosemide by sepsis/septic shock & 3.27 & $1.57-6.80$ & 2.67 & $0.89-8.00$ \\
\hline
\end{tabular}

A multivariate logistic regression test was used to establish predictors of acute kidney injury. MAP $1=$ mean arterial pressure on admission; MAP 2 = mean arterial pressure on maximum creatinine. 
0.04). The median total dose of furosemide in the subgroup of patients without sepsis/septic shock who developed AKI was $120, I Q R=360$ vs $50, I Q R=140$ for those who did not develop AKI ( $P=0.08$; Table 3$)$.

There was a moderate correlation between maximum creatinine during hospitalization and total dose of furosemide when patients without sepsis/septic shock were analyzed, rho $=0.46(P=0.007 ;$ Figure 1$)$.

In the subgroup of patients who developed sepsis/septic shock, the median maximum creatinine was significantly higher for patients who used furosemide when compared to those who did not use it: $1.70, I Q R=1.20$ vs $1.25, I Q R=$ 0.58 , respectively, $P=0.04$. In the subgroup of patients who did not develop sepsis/septic shock, the median maximum creatinine was also significantly higher for patients who used furosemide when compared to those who did not use it: $1.10, I Q R=0.30$ vs $1.00, I Q R=0.40$, respectively, $P=$ 0.05 (Figures 2 and 3).

\section{Discussion}

Studies conducted in European and/or North American countries have shown an incidence of $\mathrm{AKI}$ between 30 and $67 \%$ in critically ill patients depending on the criteria used to define it (10-13).

The mean age of the present furosemide group was greater than the non-furosemide group. GFR falls with age and therefore the furosemide group could have been more vulnerable to the development of AKI (14). Nevertheless, age was not a predictor of AKI in multivariate analysis. The non-furosemide group had a greater proportion of Afrodescendents compared to the furosemide group. This difference can be a reflex of the difficulty to establish ethnicity in a highly miscegenated population such as the Brazilian one (15). MAP was lower in the furosemide group compared to the non-furosemide group but sufficient to maintain good kidney perfusion. This difference could be explained by the use of furosemide. Mean HR was higher in the furosemide group compared to the non-furosemide group. The use of furosemide may lead to reflex tachycardia (16). Mean $\mathrm{PaO}_{2} / \mathrm{FiO}_{2}$ was lower in the furosemide group compared to the non-furosemide group. Pulmonary congestion can explain such difference since cardiac failure was more frequent in the furosemide group compared to the non-furosemide group. Mean hematocrit was lower in the

Table 3. Time in days and total dose of furosemide according to the presence of sepsis/septic shock and development of acute kidney injury (AKI).

\begin{tabular}{|c|c|c|}
\hline Factor & $\begin{array}{l}\text { With sepsis/septic shock } \\
\qquad(N=38)\end{array}$ & $\begin{array}{l}\text { Without sepsis/septic shock } \\
\qquad(\mathrm{N}=94)\end{array}$ \\
\hline Time in days of furosemide use & $\begin{array}{l}\text { AKI } 4.0 ; I Q R=6.5 \\
\text { Non-AKI } 7.5 ; \text { IQR }=7.0 \\
P \text { value }=0.41\end{array}$ & $\begin{array}{l}\text { AKI 3.0; IQR = } 6.0 \\
\text { Non-AKI 1.0; IQR = } 3.0 \\
P \text { value }=0.04\end{array}$ \\
\hline Total dose of furosemide $(\mathrm{mg} / 24 \mathrm{~h})$ & $\begin{array}{l}\text { AKI 220; IQR }=270 \\
\text { Non-AKI 280; IQR = } 240 \\
P \text { value = } 0.52\end{array}$ & $\begin{array}{l}\text { AKI 120; IQR = } 360 \\
\text { Non-AKI } 50 ; I Q R=140 \\
P \text { value }=0.08\end{array}$ \\
\hline
\end{tabular}

Data are reported as medians and interquartile range (IQR). The Mann-Whitney test was used to compare medians.

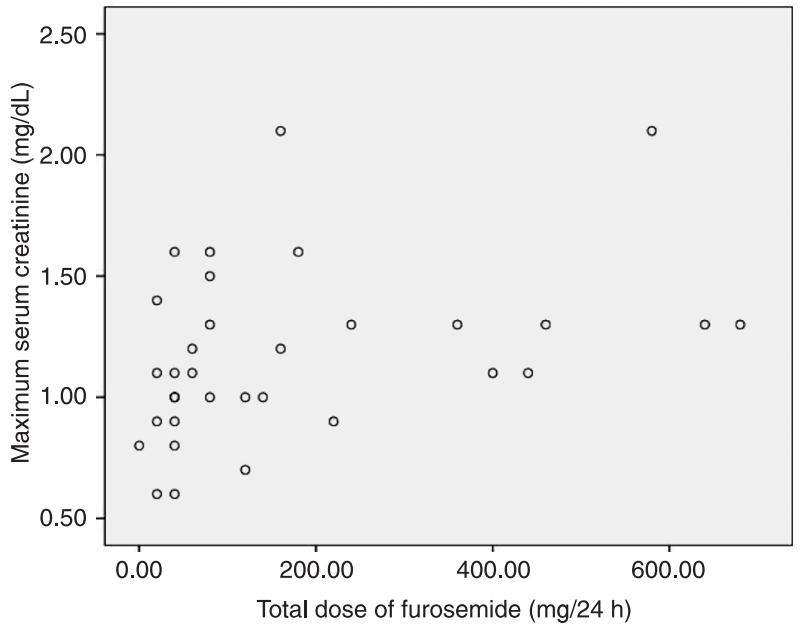

Figure 1. Spearman correlation between maximum serum creatinine and total dose of furosemide in the subgroup of patients without sepsis/septic shock. Spearman correlation: rho $=0.46$, $\mathrm{P}=0.007$.

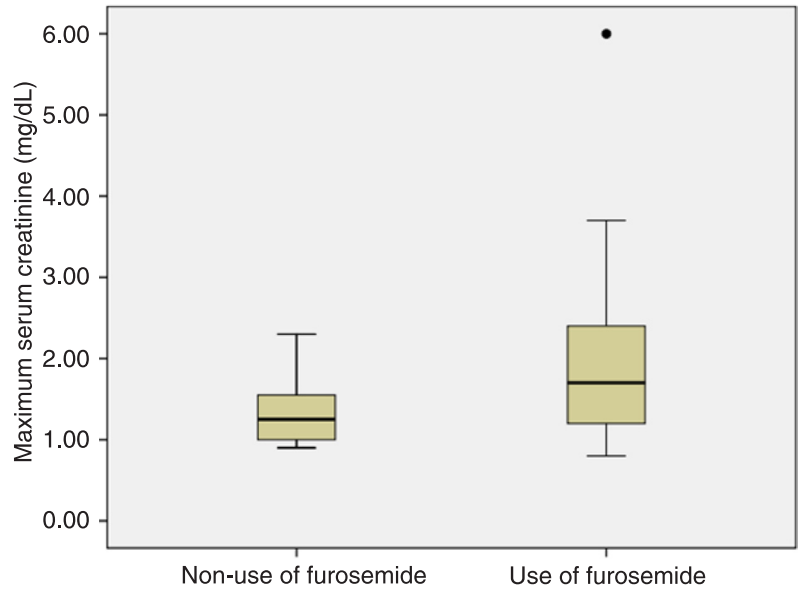

Figure 2. Boxplots representing maximum serum creatinine according to the use of furosemide in the subgroup of patients with sepsis/septic shock. Circle indicates outlier. Mann-Whitney test $(P=0.04)$. 
furosemide group compared to the non-furosemide group but not lower than $25 \%$ (a recent study demonstrated that hemodilution to hematocrits lower than $25 \%$ is associated with an increased risk for renal injury as measured by changes in serum creatinine) (17). Mean Glasgow score was lower in the furosemide group compared to the non-furosemide group. A residual effect of anesthetics could explain this difference since the percentage of patients from the surgical center was higher in the group using furosemide.

We found that occurrence of sepsis/septic shock and use of furosemide were predictors of AKI in univariate analysis, although we did not find independent predictors of $A K I$ in multivariate regression. The literature emphasizes that $\mathrm{AKI}$ in the ICU is often multifactorial and develops through a combination of factors such as hypovolemia, sepsis, hemodynamic disorders, and medications $(10-13,18,19)$. The renal ischemia that occurs in septic shock associated with hypovolemia due to the use of furosemide could simultaneously act to induce a decrease in GFR.

When analyzing only the subgroup with sepsis/septic shock, the use of furosemide was associated with the development of $A K I(O R=5.5)$, suggesting that the presence of sepsis/septic shock and use of furosemide would have a synergistic action, increasing the risk of developing AKI in critically ill patients.

The kidney injury in sepsis is a direct or indirect consequence of bacterial toxins plus global or regional hypoperfusion, microthrombosis, hypoxia, oxidative stress, and endothelial dysfunction (20-23). Although this is an entity still poorly understood, it has been recognized that an adequate renal blood flow in sepsis is imperative in order to avoid any additional damage to the kidney tissue. The main threat to renal blood flow in sepsis is typically low cardiac output secondary to low effective intravascular volume and renal perfusion pressure $(24,25)$. The Surviving Sepsis Guidelines recommend that the extracellular volume and cardiac output should be properly maintained including blood volume and pressure support to obtain an MAP above $65 \mathrm{mmHg}$ and a central venous pressure between 8 and $12 \mathrm{mmHg}$ (26-28). Rivers et al. (28) demonstrated that an early administration of fluids, vasopressors, blood products, and inotropes to maintain central venous oxygen saturation greater than $70 \%$ has an important role in decreasing mortality and also reduces the occurrence of multiple organ failure related to sepsis.

The physiological renal blood supply is very heterogeneous: approximately $90 \%$ of it is directed to the renal cortex, which performs functions such as glomerular filtration and tubular transport. The renal medulla plays the role of urinary concentration, receiving about $10 \%$ of the total blood supply. This heterogeneous perfusion explains why, despite an overall good blood supply, there is an increased susceptibility to hypoperfusion and ischemic damage in the tubular segments located in the renal medulla, i.e., the pars recta of the proximal tubule (S3 segment) and the ascend-

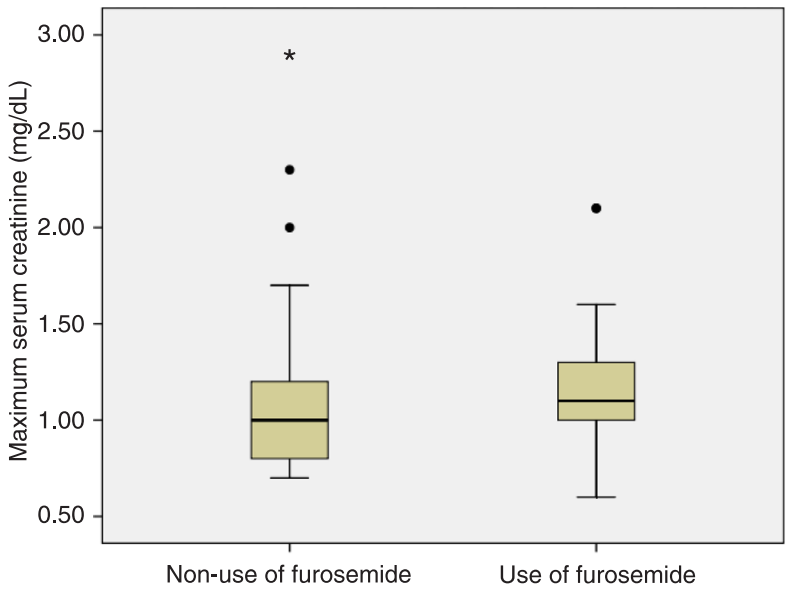

Figure 3. Boxplots representing maximum serum creatinine according to the use of furosemide in the subgroup of patients without sepsis/septic shock. Circles and asterisk indicate outliers and extreme value, respectively. Mann-Whitney test $(P=0.05)$

ing branch of the loop of Henle $(29,30)$.

The intrarenal vascular tone depends on the balance between salt-retaining vasoconstrictor systems such as the sympathetic axis, renin-angiotensin-aldosterone system and arginine vasopressin and salt-excreting vasodilators such as prostaglandins, atrial natriuretic peptide, kinins, and nitric oxide. Reductions in the effective volume of, the renal artery lead to sympathetic stimulation and production of angiotensin II, with a preferential vasoconstriction in the renal cortex resulting in a redistribution of renal blood flow in favor of the vulnerable medulla (31-33).

Some explanations can be proposed for the presence of the deleterious effect of diuretics on renal function in critically ill patients with sepsis/septic shock: a) reduction in preload with renal vasoconstriction, activation of the renin-angiotensin-aldosterone system and sympathetic stimulation (this reduction in preload occurs not only by increased urine output induced by furosemide, but also by a prostaglandin-mediated venodilation) $(34,35)$; b) Dobrowolski et al. $(36,37)$ demonstrated a pronounced decrease in medullary blood flow compared to the cortex after administration of furosemide. The differential effect of furosemide on cortical and medullary blood flow may increase the intrarenal risk of medullar ischemia, favoring the development of acute tubular necrosis (36-38). One can suggest that the reduction of preload and medullary blood flow mediated by furosemide in patients with sepsis/ septic shock may have been the cause of the increased risk of $\mathrm{AKI}$ in patients with sepsis/septic shock compared to the total sample.

The use of furosemide was not associated with the development of $\mathrm{AKI}$ in the group without sepsis/septic shock. Nevertheless, the median time in days of use of furosemide and its total dose were significantly higher in those who 
developed AKI than in those who did not develop it. The maximum creatinine had a moderate correlation with the total dose of furosemide in the subgroup without sepsis/ septic shock. The median maximum creatinine in those who did not develop sepsis/septic shock was significantly higher in patients using furosemide compared to those who did not use it. Such findings indicate the need for further investigation on the association between the use of furosemide and development of $\mathrm{AKI}$ in patients without sepsis/septic shock.

\section{References}

1. Hilton R. Acute renal failure. BMJ 2006; 333: 786-790.

2. Mehta RL, Kellum JA, Shah SV, Molitoris BA, Ronco C, Warnock DG, et al. Acute Kidney Injury Network: report of an initiative to improve outcomes in acute kidney injury. Crit Care 2007; 11: R31.

3. Bucuvic EM, Ponce D, Balbi AL. Risk factors for mortality in acute kidney injury. Rev Assoc Med Bras 2011; 57: 158163.

4. Samimagham HR, Kheirkhah S, Haghighi A, Najmi Z. Acute kidney injury in intensive care unit: incidence, risk factors and mortality rate. Saudi J Kidney Dis Transpl 2011; 22: 464-470.

5. Dennen P, Douglas IS, Anderson R. Acute kidney injury in the intensive care unit: an update and primer for the intensivist. Crit Care Med 2010; 38: 261-275.

6. Mehta RL, Pascual MT, Soroko S, Chertow GM. Diuretics, mortality, and nonrecovery of renal function in acute renal failure. JAMA 2002; 288: 2547-2553.

7. Ho KM, Sheridan DJ. Meta-analysis of frusemide to prevent or treat acute renal failure. BMJ 2006; 333: 420.

8. Shilliday IR, Quinn KJ, Allison ME. Loop diuretics in the management of acute renal failure: a prospective, doubleblind, placebo-controlled, randomized study. Nephrol Dial Transplant 1997; 12: 2592-2596.

9. Uchino S, Doig GS, Bellomo R, Morimatsu H, Morgera S, Schetz M, et al. Diuretics and mortality in acute renal failure. Crit Care Med 2004; 32: 1669-1677.

10. Uchino S, Kellum JA, Bellomo R, Doig GS, Morimatsu H, Morgera $S$, et al. Acute renal failure in critically ill patients: a multinational, multicenter study. JAMA 2005; 294: 813818.

11. Uchino S, Bellomo R, Goldsmith D, Bates S, Ronco C. An assessment of the RIFLE criteria for acute renal failure in hospitalized patients. Crit Care Med 2006; 34: 1913-1917.

12. Mehta RL, Pascual MT, Soroko S, Savage BR, Himmelfarb J, Ikizler TA, et al. Spectrum of acute renal failure in the intensive care unit: the PICARD experience. Kidney Int 2004; 66: 1613-1621.

13. Ostermann M, Chang RW. Acute kidney injury in the intensive care unit according to RIFLE. Crit Care Med 2007; 35: 1837-1843.

14. Davies DF, Shock NW. Age changes in glomerular filtration rate, effective renal plasma flow, and tubular excretory capacity in adult males. J Clin Invest 1950; 29: 496-507.

15. Suarez-Kurtz G. Pharmacogenomics and the genetic diversity of the Brazilian population. Cad Saúde Pública 2009; 25:
We found that use of furosemide is associated with development of AKI in patients with sepsis/septic shock, a very frequent clinical condition in critically ill patients. The subgroups divided according to use of furosemide or not were heterogeneous and multivariate analysis did not find an independent predictor of AKI. New observational studies with more homogeneous subgroups and randomized clinical trials are necessary to clarify if there is a causal association between use of furosemide and $A K I$ in patients with sepsis/septic shock.
1650-1651.

16. Mattu A, Martinez JP, Kelly BS. Modern management of cardiogenic pulmonary edema. Emerg Med Clin North Am 2005; 23: 1105-1125.

17. Karkouti K, Beattie WS, Wijeysundera DN, Rao V, Chan $\mathrm{C}$, Dattilo KM, et al. Hemodilution during cardiopulmonary bypass is an independent risk factor for acute renal failure in adult cardiac surgery. J Thorac Cardiovasc Surg 2005; 129 : 391-400.

18. Lassnigg A, Schmidlin D, Mouhieddine M, Bachmann LM, Druml W, Bauer P, et al. Minimal changes of serum creatinine predict prognosis in patients after cardiothoracic surgery: a prospective cohort study. J Am Soc Nephrol 2004; 15: 1597-1605.

19. Vivino G, Antonelli M, Moro ML, Cottini F, Conti G, Bufi M, et al. Risk factors for acute renal failure in trauma patients. Intensive Care Med 1998; 24: 808-814.

20. Bellomo R, Wan L, May C. Managing septic acute renal failure: "fill and spill"? "squeeze and diurese"? or "block Bax to the max"? Crit Care Resusc 2004; 6: 12-16.

21. Molitoris BA, Sandoval RM. Intravital multiphoton microscopy of dynamic renal processes. Am J Physiol Renal Physiol 2005; 288: F1084-F1089.

22. Wu L, Gokden N, Mayeux PR. Evidence for the role of reactive nitrogen species in polymicrobial sepsis-induced renal peritubular capillary dysfunction and tubular injury. J Am Soc Nephrol 2007; 18: 1807-1815.

23. Dagher PC, Herget-Rosenthal S, Ruehm SG, Jo SK, Star RA, Agarwal R, et al. Newly developed techniques to study and diagnose acute renal failure. J Am Soc Nephrol 2003; 14: $2188-2198$.

24. Langenberg C, Bellomo R, May CN, Egi M, Wan L, Morgera S. Renal vascular resistance in sepsis. Nephron Physiol 2006; 104: 1-11.

25. Molitoris BA. Renal blood flow in sepsis: a complex issue. Crit Care 2005; 9: 327-328.

26. Dellinger RP, Carlet JM, Masur H, Gerlach H, Calandra T, Cohen J, et al. Surviving Sepsis Campaign guidelines for management of severe sepsis and septic shock. Crit Care Med 2004; 32: 858-873.

27. Russell JA. Management of sepsis. N Engl J Med 2006; 355: 1699-1713.

28. Rivers E, Nguyen B, Havstad S, Ressler J, Muzzin A, Knoblich B, et al. Early goal-directed therapy in the treatment of severe sepsis and septic shock. N Engl J Med 2001; 345: $1368-1377$ 
29. Brezis M, Rosen S. Hypoxia of the renal medulla - its implications for disease. N Engl J Med 1995; 332: 647-655.

30. Sheridan AM, Bonventre JV. Pathophysiology of ischemic acute renal failure. Contrib Nephrol 2001; 7-21.

31. Cohen J. The immunopathogenesis of sepsis. Nature 2002; 420: 885-891.

32. Evans RG, Madden AC, Denton KM. Diversity of responses of renal cortical and medullary blood flow to vasoconstrictors in conscious rabbits. Acta Physiol Scand 2000; 169: 297308.

33. Guild SJ, Eppel GA, Malpas SC, Rajapakse NW, Stewart A, Evans RG. Regional responsiveness of renal perfusion to activation of the renal nerves. Am J Physiol Regul Integr Comp Physiol 2002; 283: R1177-R1186.

34. Silke B. Haemodynamic impact of diuretic therapy in chronic heart failure. Cardiology 1994; 84 (Suppl 2): 115-123.

35. Pickkers P, Dormans TP, Russel FG, Hughes AD, Thien T, Schaper N, et al. Direct vascular effects of furosemide in humans. Circulation 1997; 96: 1847-1852.

36. Dobrowolski L, Baddzynska B, Sadowski J. Differential effect of frusemide on renal medullary and cortical blood flow in the anaesthetised rat. Exp Physiol 2000; 85: 783-789.

37. Dobrowolski L, Badzynska B, Grzelec-Mojzesowicz M, Sadowski J. Renal vascular effects of frusemide in the rat: influence of salt loading and the role of angiotensin II. Exp Physiol 2001; 86: 611-616.

38. Castrop H, Vitzthum H, Schumacher K, Schweda F, Kurtz A. Low tonicity mediates a downregulation of cyclooxygenase-1 expression by furosemide in the rat renal papilla. $J$ Am Soc Nephrol 2002; 13: 1136-1144. 